\title{
Isolation of Endophytic Fungi QPS 05 from Quercus phillyraeoides A. Gray and Its Potential for $\alpha$-Glucosidase Inhibitory Activity
}

\author{
Anastasia Wheni Indrianingsih ${ }^{1^{*}}$ Amalia Indah Prihantini ${ }^{2}$, Sanro Tachibana ${ }^{3}$ \\ ${ }^{1}$ Research Unit for Natural Products Technology, Indonesian Institute of Sciences, Gading, Playen, Gunungkidul, \\ Yogyakarta, 55581, Indonesia \\ ${ }^{2}$ Research, Development and Innovation Agency, Ministry of Environment and Forestry - Republic of Indonesia, Jl. \\ Raya Gunung Batu No. 5, Bogor 16001, Indonesian \\ ${ }^{3}$ Department of Applied Biosciences, Faculty of Agriculture, Ehime University, 3-5-7 Tarumi Matsuyama, Ehime 790- \\ 8566, Japan \\ *Corresponding author : anastasia_wheni_i@yahoo.com; anas004@lipi.go.id
}

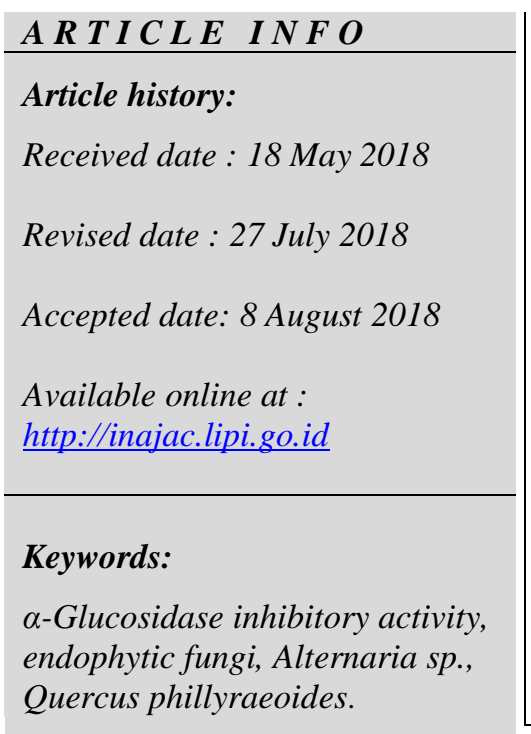

\section{Abstract}

Endophytic fungi are the microorganisms that spend all or part of their life cycles within plant tissue without causing harmful effects on the plant. In this study, 14 endophytic fungus from Quercus phillyraeoides A. Gray were isolated. Alternaria sp. QPS 05, an endophytic fungi which was isolated from the stem of $Q$. phillyraeoides A. Gray showed the highest $\alpha$-glucosidase inhibitory activity. Further separation of ethyl acetate extract from the fungus led to the isolation of active substance from hexane-soluble fraction which give fatty acids mixture consist of palmitic acid, oleic acid, linoleic acid and linolenic acid (1) strong inhibitory activity against $\alpha$-glucosidase. Isolated fatty acids (1) had inhibitory concentration $\left(\mathrm{IC}_{50}\right)$ values against Saccharomyces cerevisiae was $12.10 \mu \mathrm{g} / \mathrm{mL}$. The results of the present study showed that endophytic fungus from Alternaria sp. QPS 05 potentially contained a rich source of natural antidiabetic medicine.

(C) 2018 Indonesian Journal of Applied Chemistry. This is an open access article under the CC BY-NC-SA license (https://creativecommons.org/licenses/by-nc-sa/4.0/).

\section{INTRODUCTION}

Diabetes mellitus (DM) is a severe disease due to its related complications. There are two types of DM: type 1 and type 2 . Type $1 \mathrm{DM}$ is caused by the destruction of pancreatic beta cells, while type $2 \mathrm{DM}$ is resulted from defects in insulin secretion [1]. DM is characterized by high blood glucose levels, which lead to bad effects on health such as retinopathy, nephropathy, diabetic foot ulcers and hypertension, and neuropathy [2]. Approximately, $80 \%$ of DM cases is type $2 \mathrm{DM}$ [3]. By 2030, it was estimated that the number of DM patients will rise to 366 million [4].

Development of drugs and pharmaceuticals without any side effects is needed since current DM treatments are based on the use of synthetic drugs, which have several serious adverse effects [5]. Approximately 1200 plants in the world had been identified having antidiabetic potential [6]. The application of medicine or drugs from natural compound isolated from nature is suggested due to its fewer side effects than those of synthetic medicines $[7,8]$. Therefore, the research on the field of isolation of natural compounds for antidiabetic treatments has been increasing in the recent years $[9,10]$.

Endophytic fungi are the microorganisms that spend all or part of their life cycles within plant tissue without causing harmful effects on the plant [11]. Endophytic fungi usually obtain nutrition from their host plant and produce certain bioactive metabolites [12]. Recent research presented that endophytic fungi have capability to produce many new compounds that could be use as pharmaceuticals or source of bioactive compounds, such as antioxidant [13], antibacterial [14], antifungal [15], antiviral [16], and antidiabetic [17]. Q. phillyraeoides of 
the family Fagaceae is an evergreen tree that is distributed in the acid bed rocks and limestone mountains of East Asia (Japan, Korea, and China). The leaves of Quercus species have been used in Korean folk medicine for dysentery, hemorrhage, diarrhea, and dermatitis [18]. In our previous study, we found that several active constituents were isolated from $Q$. phillyraeoides [19], therefore in this study we conducted isolation of endophytic fungi from $Q$. phillyraeoides and evaluate its $\alpha$ glucosidase inhibitory activity.

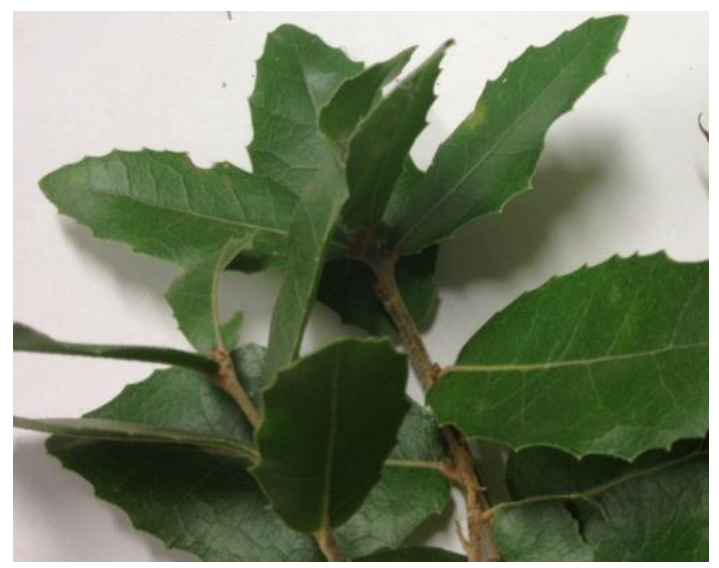

Fig. 1. Quercus phillyraeoides A. Gray

\section{EXPERIMENTAL SECTION}

\subsection{Chemicals}

Enzyme $\alpha$-glucosidase from $S$. cerevisiae, $p$ nitrophenyl-d-glucopyranoside ( $p$-NPG) and bis(trimethylsilyl) acetamide (BSA) were purchased from Wako Pure Chemicals, Ltd. (Osaka, Japan). Quercetin, palmitic acid, stearic acid, oleic acid, linoleic acid, and linolenic acid were purchased from Sigma-Aldrich Co., Ltd. (Tokyo, Japan). The solvents used in this research were obtained from Wako Pure Chemicals, Ltd.

\subsection{Isolation and culture of the endophytic fungi}

The leaves and stems of Quercus phillyraeoides A. Gray were collected from Ehime University Garden, Ehime Prefecture, Japan. Samples were cleaned in tap water and sterilized by consecutive washes in $75 \% \mathrm{EtOH}$ ( $1 \mathrm{~min}$ ), $1 \% \mathrm{NaOCl}$ (2 min), $75 \% \mathrm{EtOH}(30 \mathrm{~s})$ and rinsed with sterile distilled $\mathrm{H}_{2} \mathrm{O}$. The surface sterilized material was cut into $0.4 \mathrm{x} 0.4$ $\mathrm{cm}$ pieces and the tissues were deposited on a petri dish containing potato dextrose agar (PDA) medium and incubated at $25^{\circ} \mathrm{C}$. The hyphal of fungi was transferred to fresh PDA medium and purified for three times.

\subsection{Fermentation and extraction}

Fourteen endophytic fungi were inoculated into the Erlenmeyer flasks $(500 \mathrm{~mL})$ at $25^{\circ} \mathrm{C}$ for 3 weeks. Each flask containing $200 \mathrm{~mL}$ potato dextrose broth (PDB). Mycelium and filtrate (filtered medium) were separated and extracted with equal volume of ethyl acetate at room temperature. The extract of each endophytic fungus was condensed in a rotating evaporator under reduced pressure and evaluated the $\alpha$ glucosidase inhibitory activity.

\section{4. $\alpha$-Glucosidase inhibitory assay}

Samples were dissolved in dimethyl sulfoxide at various concentrations $(10 \mu \mathrm{L})$ and treated with p-NPG $(250 \mu \mathrm{L}, 3 \mathrm{mM})$ and phosphate buffer solution $(490 \mu \mathrm{L}, 100 \mathrm{mM}$, $\mathrm{pH} 7$ ). The solution was pre-incubated at $37^{\circ} \mathrm{C}$ for $5 \mathrm{~min}$. Then, $250 \mu \mathrm{L}$ of $\alpha$-glucosidase enzyme $(0.065 \mathrm{U} / \mathrm{mL})$ was added and the reaction continued for $15 \mathrm{~min}$. The reaction was stopped by adding $1 \mathrm{~mL}$ of $0.2 \mathrm{M} \mathrm{Na}_{2} \mathrm{CO}_{3}$. The mixtures were measured at $400 \mathrm{~nm}$ using a UVVis spectrophotometer [20]. The inhibitory concentration $\left(\mathrm{IC}_{50}\right)$ was evaluated using analysis of regression from a graph by plotting $\alpha$-glucosidase inhibitory activity against concentration.

\subsection{Molecular identification of fungus}

Endophytic fungus with the most active extract on $\alpha$-glucosidase inhibitory activity was further determined using molecular identification. Fungal strains were maintained on PDA and incubated for 7 days. DNA was extracted from these fungi based on the Doyle and Doyle [21] method with a slight modification. The extracted DNA was used as a template for PCR to amplify the ITS1-F and ITS4-B regions. Products were then sequenced using two PCR primers and an automated ABI Prism DNA sequence. The result of sequencing was compared with the National Centre for Biotechnology Information (NCBI) GenBank database. 
A phylogenetic tree was constructed using MEGA software (version 5.2.2). The endophytic fungus was identified as Alternaria sp. QPS 05 (GenBank accession number: KU870896).

\section{Isolation of active substance and GC-MS analysis of fatty acid mixture}

The ethyl acetate extract (4.56 g) was partitioned using hexane to obtain hexane soluble. Active substance $\mathbf{1}$ (fatty acids mixture) was obtained from the $n$-hexane soluble using alkali solution. The methylation of fatty acids was conducted using methanol which was acidified with sulphuric acid at $64{ }^{\circ} \mathrm{C}$ for $30 \mathrm{~min}$ to form Fatty Acid Methyl Ester (FAME). Chemical analysis was conducted using gas chromatography coupled with mass spectrometry (GC-MS QP-2010) equipped with a SPB-50 column $(30 \mathrm{~m} \times 0.25 \mathrm{~mm}$ ID, $0.25 \mathrm{~m}$ film thickness). The analysis was performed according to Yamamoto et al., 2008 [22], column temperature, $235^{\circ} \mathrm{C}$, carrier gas helium linear gas velocity, $30 \mathrm{~cm} / \mathrm{sec}$; split ratio, 1/30, ion source temperature, $200^{\circ} \mathrm{C}$ and interface temperature, $280^{\circ} \mathrm{C}$. The identification of chemicals was performed in comparison with database (NIST08 library) and confirmed using authentic standard samples.

\section{RESULT AND DISCUSSION}

\subsection{Screening of $\alpha$-glucosidase inhibitory activity}

Type 2 of DM patient need $\alpha$-glucosidase inhibitors for an agent to delay glucose absorption, and since several unwanted effects were found from the synthetic antidiabetic drugs, a safe $\alpha$-glucosidase inhibitors from nature were sought. The evaluation of $\alpha$ glucosidase inhibitory activity of ethyl acetate extracts of 14 fungi from the leaves and stem of $Q$. phillyraeoides was shown in Table 1 and Table 2, respectively. The $\mathrm{IC}_{50}$ of the endophytic fungi extracts from the leave (QPL) ranged from 73 to $>500 \mathrm{ppm}$ from the mycelium and from 174 to $>500 \mathrm{ppm}$ from the filtrate. Meanwhile, the $\mathrm{IC}_{50}$ of the endophytic fungi extracts from the stem (QPS) ranged from
12.7 to $>500 \mathrm{ppm}$ from the mycelium and from 24 to $>500 \mathrm{ppm}$ from the filtrate.

Table 1. $\alpha$-Glucosidase inhibitory activity of endophytic fungi from the leaves (QPL) of Quercus phillyraeoides A. Gray

\begin{tabular}{ccc}
\hline $\begin{array}{c}\text { Fungi } \\
\text { extract }\end{array}$ & $\begin{array}{c}\text { Mycelium, a-gluc. } \\
\text { activity, IC } \mathbf{5 0}, \\
\text { ppm }\end{array}$ & $\begin{array}{c}\text { Filtrate, } \boldsymbol{\alpha} \text {-gluc. } \\
\text { activity, IC } \mathbf{5 0}, \\
\text { ppm }\end{array}$ \\
\hline QPL 01 & $258 \pm 15$ & $>500$ \\
QPL 02 & $221 \pm 13$ & $457 \pm 34$ \\
QPL 03 & $>500$ & $479 \pm 32$ \\
QPL 04 & $>500$ & $350 \pm 25$ \\
QPL 05 & $>500$ & $>500$ \\
QPL 06 & $73 \pm 6.3$ & $174 \pm 14$ \\
QPL 07 & $94 \pm 7.8$ & $319 \pm 22$ \\
Quercetin & $4.25 \pm 0.6$ & \\
\hline
\end{tabular}

Table 2. $\alpha$-Glucosidase inhibitory activity of endophytic fungi from the stem (QPS) of Quercus phillyraeoides A. Gray

\begin{tabular}{ccc}
\hline $\begin{array}{c}\text { Fungi } \\
\text { extract }\end{array}$ & $\begin{array}{c}\text { Mycelium, } \boldsymbol{\alpha - g l u c} \\
\text { activity, IC } \\
\text { ppm }\end{array}$ & $\begin{array}{c}\text { Filtrate, } \boldsymbol{\alpha} \text {-gluc. } \\
\text { activity, IC50, } \mathbf{~ p p m}\end{array}$ \\
\hline QPS 01 & $118 \pm 8.4$ & $311 \pm 25$ \\
QPS 02 & $41 \pm 3.4$ & $326 \pm 24$ \\
QPS 03 & $113 \pm 8.9$ & $233 \pm 19$ \\
QPS 04 & $>500$ & $>500$ \\
QPS 05 & $\mathbf{1 2 . 7 \pm 0 . 9}$ & $\mathbf{2 4 \pm 1 . 2}$ \\
QPS 06 & $52 \pm 4.3$ & $155 \pm 12$ \\
QPS 07 & $49 \pm 3.9$ & $96 \pm 7.8$ \\
Quercetin & $4.25 \pm 0.6$ & \\
\hline
\end{tabular}

Among the fungi extracts, the highest $\alpha$ glucosidase inhibitory activity was the mycelium of QPS 05 fungus. The mycelium of QPS 05 fungus was further separated to obtain the most active substance on $\alpha$-glucosidase inhibitory activity.

\subsection{Identification of endophytic fungi}

The endophytic fungus of QPS 05 isolated from the stem of $Q$. phillyraeoides is shown in Fig. 2. According to a molecular gene analysis, strain endophytic fungus QPS 05 was similar (99-100\%) to Alternaria sp. (GenBank accession number: KU870896). A phylogenetic tree of Alternaria sp. QPS 05 is shown in Fig. 3. Identification was conducted in Forest Genetic Laboratory, Ehime University using ABI PRISM ${ }^{\mathrm{TM}} 310$ Genetic Analyzer (Applied Biosystem). 


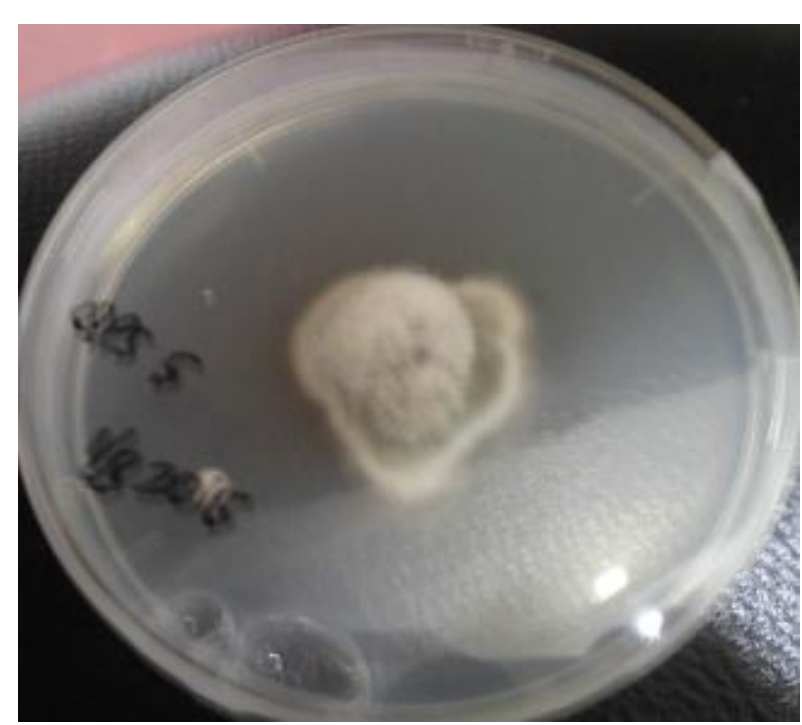

Fig. 2. Endophytic fungus QPS 05 from the stem of Q. phillyraeoides

Alternaria is an ascomycete fungi and has a wide biological diversity. Several Alternaria sp. were isolated as endophytic fungi from several plants such as endophytic fungus Alternaria sp. G7 from $B$. papyrifera which had many bioactive substances, such as (altertoxin IV, 3,4',5'-trihydroxy-5-methoxy-6H-benzo[c] chromen-6-one, alternariol 4'-O- ethyl ether, altersolanol A, altertoxin I, ergosta-4, 6, 8, ergone, alternariol 5-O-methyl ether, alternariol, alternuene, altersolanol) and also had cytotoxic activity against three human cancer cell lines [23]. Endophytic fungus Alternaria sp. from the roots of $S$. miltiorrhiza Bunge which was isolated also had antibacterial activity [24].

\subsection{Isolation of a-glucosidase inhibitory active substances}

Between the mycelium and the culture broth extracts, the mycelium of QPS 05 fungus $\left(\mathrm{IC}_{50}\right.$ $=12.70 \mathrm{~g} / \mathrm{mL}$ ) has the highest $\alpha$-glucosidase inhibitory activity. Therefore, it was further separated to obtain the most active substance on $\alpha$-glucosidase inhibitory activity. Active substance 1 (fatty acids mixture) was obtained from the $n$-hexane soluble using alkali solution. Figure 4 shows gas chromatogram profile of the isolated fatty acids: (1) palmitic acid methyl ester, (2) stearic acid methyl ester, (3) oleic acid methyl ester, (4) linoleic acid methyl ester, (5) linolenic acid methyl ester while Fig. 5 shows the MS spectra of the fatty acid derivatives. Substance 1 (fatty acid mixture) had one saturated fatty acids, palmitic acid (C16:0) and three unsaturated fatty acids, namely oleic acid (C18:1), linoleic acid (C18:2) and linolenic acid (C18:3).

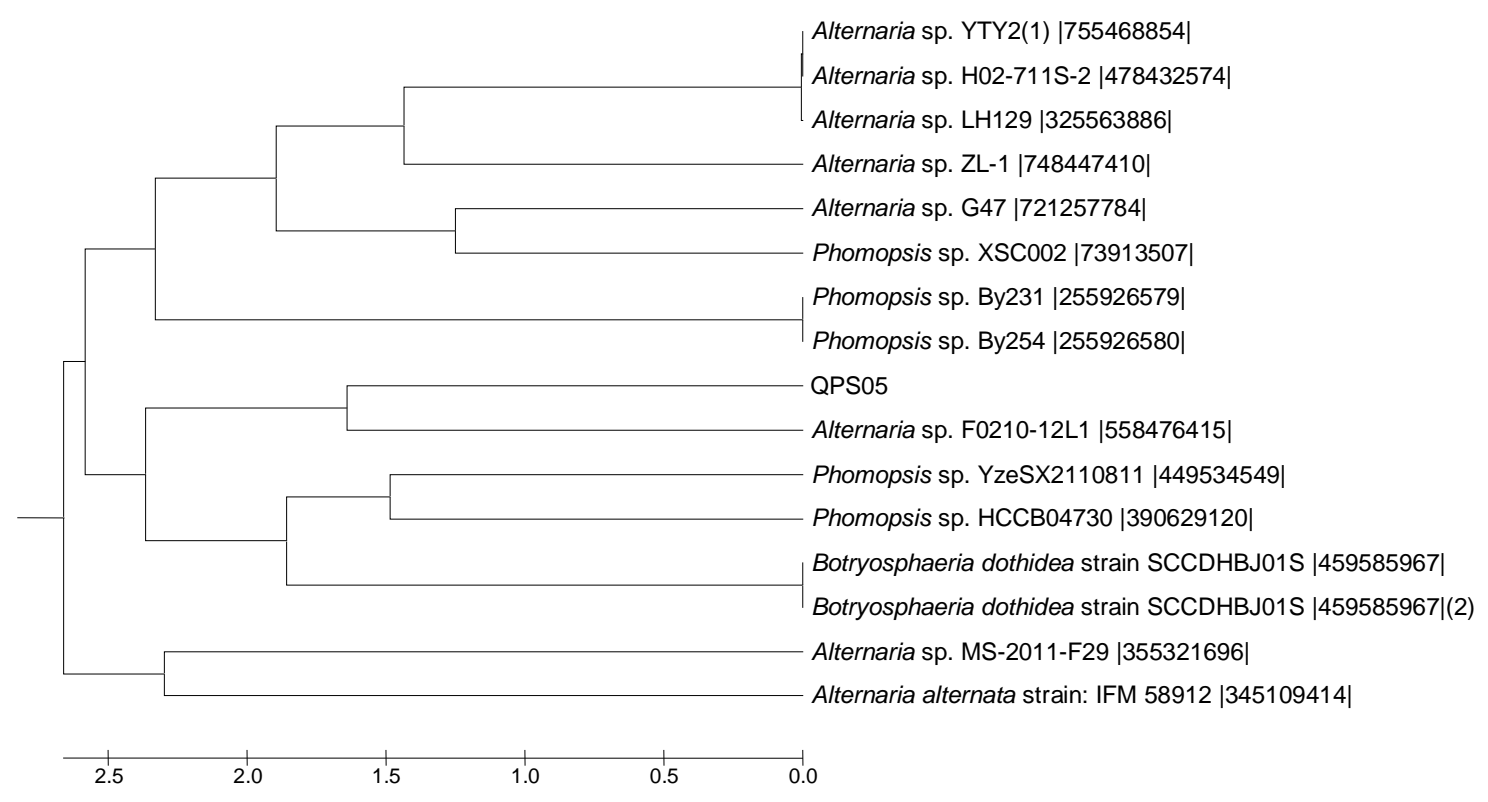

Fig. 3. Phylogenetic tree for endophytic fungus QPS 05 based on ITS sequences. 


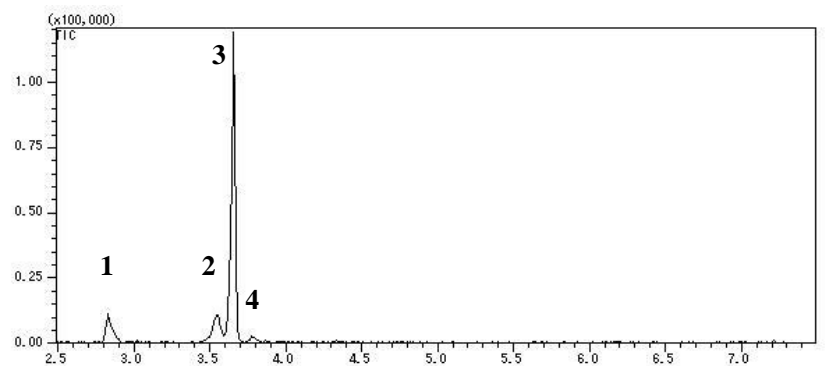

Fig. 4. Gas chromatogram profile of isolated fatty acids: (1) palmitic acid methyl ester, (2) oleic acid methyl ester, (3) linoleic acid methyl ester, (4) linolenic acid methyl ester.

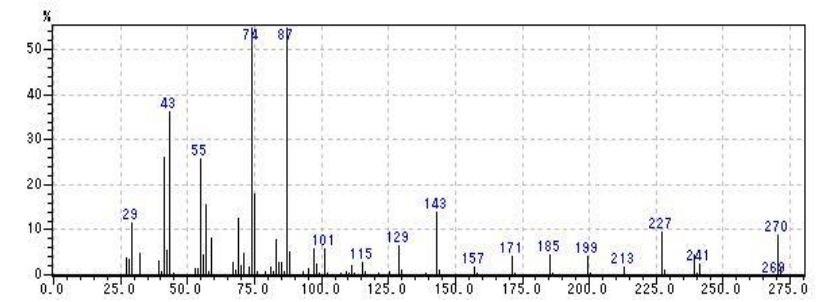

(a)

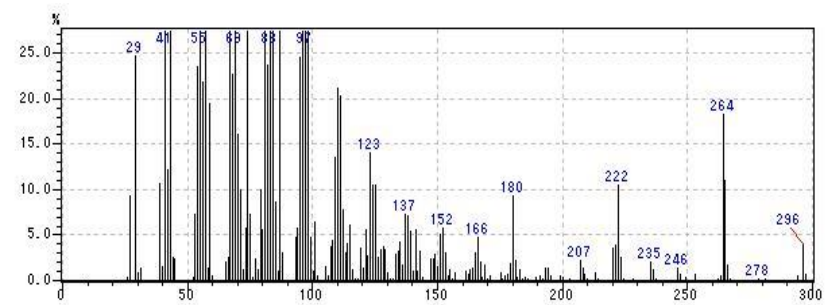

(b)

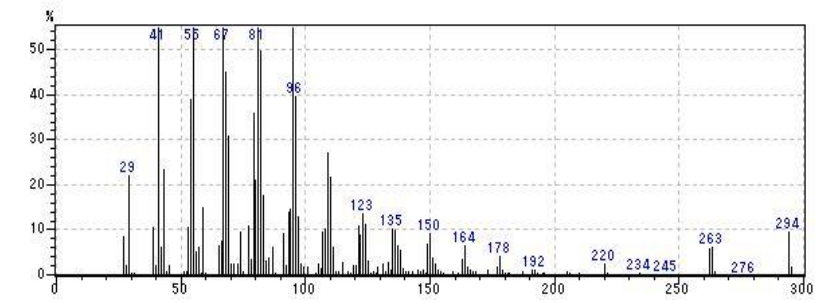

(c)

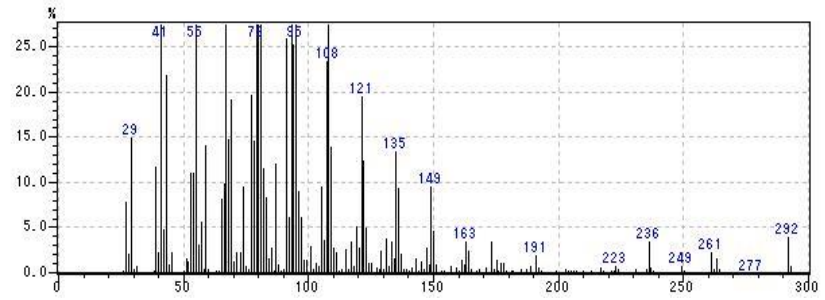

(d)

Fig. 5. MS spectra of fatty acid derivatives (a) Palmitic acid methyl ester $(\mathrm{m} / \mathrm{z} 270)$, (b) Oleic acid methyl ester $(\mathrm{m} / \mathrm{z}$ 296), (c) Linoleic acid methyl ester $(\mathrm{m} / \mathrm{z}$ 294), and (d) Linolenic acid methyl ester $(\mathrm{m} / \mathrm{z} 292)$.
$\alpha$-Glucosidase inhibitor assay were performed as anti-diabetic properties capability in the terms of the ability of the constituents to inhibit an intestinal carbohydrate-digesting enzyme ( $\alpha$-glucosidase). The $\alpha$-glucosidase inhibitors postpone intestinal carbohydrate absorption by blocking the activity of glucosidase enzyme, and consequently reduce the concentration of postprandial blood glucose and slow down the rise in blood sugar level; therefore, they have an important role for noninsulin-dependent DM. Voglibose, acarbose, and miglitol, are several examples of $\alpha$ glucosidase inhibitors currently being used in the primary treatment of type 2 DM [25]. However, since the presently available $\alpha$ glucosidase inhibitors have several side effects, a safe $\alpha$-glucosidase inhibitors from nature have been sought for the anti-diabetic medicines

Table 3 shows that substance 1 of hexane fraction from ethyl acetate extract of Alternaria sp. QPS 05 has the $\alpha$-glucosidase inhibitory activity in the amount of $12.10 \pm 0.4 \mathrm{ppm}$. This result confirms that Alternaria sp. QPS 05 are indeed a potential inhibitor againts $\alpha$ glucosidase activity.

Table 3. $\alpha$-Glucosidase inhibitory and antioxidant activities of fatty acid isolated from endophytic fungus QPS 05

\begin{tabular}{ll}
\hline \multicolumn{1}{c}{ Constituent } & $\begin{array}{c}\boldsymbol{\alpha} \text {-Glucosidase inhibitory } \\
\text { act., } \text { IC }_{\mathbf{5 0}}, \mathbf{p p m}\end{array}$ \\
\hline $\mathbf{1}$ (Fatty acids) & $12.10 \pm 0.4$ \\
Quercetin & $4.25 \pm 0.6$ \\
\hline
\end{tabular}

Several fatty acids were also reported to have $\alpha$-glucosidase inhibitory activity, such as fatty acids from sea cucumber [26], from endophytic fungus Colletotrichum sp. [27], and from wheat germ [28]. It is proposed that the presence of a double bond was significant factor of inhibition $\alpha$-glucosidase acitivity [29].

\section{CONCLUSION}

Endophytic fungi Alternaria sp. QPS 05 was isolated from the stem of Quercus phillyraeoides A. Gray and showed high activity of $\alpha$-glucosidase inhibitory activity. One active substance: fatty acids mixture (1) 
was isolated from endophytic fungi Alternaria sp. QPS 05. Substance $\mathbf{1}$ had inhibitory concentration $\left(\mathrm{IC}_{50}\right)$ values against $\alpha$ glucosidase from Saccharomyces cerevisiae in the amount of $12.10 \mu \mathrm{g} / \mathrm{mL}$.

\section{ACKNOWLEDGMENT}

The author's sincere gratitude to Prof. Leonardus Broto Sugeng Kardono (Research Center for Chemistry, LIPI), Ade Andriani, Ph.D (Research Center for Biotechnology, LIPI), and Fifi Gus Dwiyanti, Ph.D (Bogor Agricultural University) for their excellent support and assistance.

\section{REFERENCES}

[1] A.L. Notkins. Immunologic and genetic factors in type 1 diabetes, J. Biol. Chem. 277, pp. 43545-43548. (2002).

[2] S.O. Oyedemi, G. Bradley, A.J. Afolayan, Ethnobotanical survey of medicinal plants used for the management of diabetes mellitus in the Nkonkobe municipality of South Africa, J. Med. Plant. Res. 3, pp. 1040-1044. (2009).

[3] B. Mlinar, J. Marc, A. Janez, M. Pfeifer. Molecular mechanisms of insulin resistance and associated diseases, Clin. Chim. Acta 375, pp. 20-35. (2007).

[4] I. Funke, M.F. Melzig. Traditionally used plants in diabetes therapy phytotherapeutics as inhibitors of amylase activity, Braz. J. Pharmacogn. 16, pp. 1-5. (2006).

[5] B.B. Zhang, D.E. Moller. New approaches in the treatment of type 2 diabetes, Curr. Opin. Chem. Biol. 4, pp. 461-467. (2000).

[6] F.J. Alarcon-Aguilar, R. Roman-Ramos, J.L. Flores-Saenz, F. AguirreGarcia. Investigation on the hypoglycaemic effects of extracts of four Mexican medicinal plants in normal and alloxandiabetic mice, Phytother. Res. 16, pp. 383-386. (2002).
[7] M.J. Aybar, A.N. Sanchez Riera, A. Grau, S.S. Sanchez. Hypoglycemic effect of the water extract of Smallantus sonchifolius (yacon) leaves in normal and diabetic rats, J. Ethnopharmacol. 74, pp. 125-132. (2001).

[8] W.R. Cunha, G.M. Arantes, D.S. Ferreira, R. Lucarini, M.L.A. Silva, N.A.J.C. Furtado, et al. Hypoglycemic effect of Leandra lacunose in normal and alloxaninduced diabetic rats, Fitoterapia 79, pp. 356-360. (2008).

[9] A.W. Indrianingsih, S. Tachibana, R.T. Dewi, K. Itoh. Antioxidant and $\alpha$ glucosidase inhibitor activities of natural compounds isolated from Quercus gilva Blume leaves, Asian Pac. J. Trop. Biomed. 5 (9), pp.748-755. (2015).

[10] A.W. Indrianingsih, S. Tachibana, K. Itoh. In Vitro Evaluation of Antioxidant and $\alpha$-Glucosidase Inhibitory Assay of Several Tropical and Subtropical Plants, Procedia Environmental Sciences 28, pp. 639-648. (2015).

[11] D. Dutta, K.C. Puzari, R. Gogoi, P. Dutta. Endophytes: exploitation as a tool in plant protection, Braz. Arch. Biol. Technol. 57, pp. 621-629. (2014).

[12] R. Tan, W. Zou. Endophytes: a rich source of functional metabolites, Nat. Prod. Rep. 18, pp. 448-459. (2001).

[13] J.T. Zhao, Y.J. Fu, M. Luo, Y.G. Zu, W. Wang, C.J. Zhao, C.B. Gu. Endophytic fungi from pigeon pea [Cajanus cajan (L.) millsp.] produce antioxidant cajaninstilbene acid, J. Agric. Food Chem. 60, pp. 4314-4319. (2012).

[14] Y. Igarashi, H. Ogura, K. Furihata, N. Oku, C. Indananda. A. Thamchaipenet. Maklamicin, an antibacterial polyketide from an endophytic Micromonospora sp, J. Nat. Prod. 74, pp. 670-673. (2011).

[15] Y. Wang, L. Xu, W. Ren, D. Zhao, Y. Zhu, X. Wu. Bioactive metabolites from Chaetomium globosum L18, an endophytic fungus in the medicinal plant 
Curcuma wenyujin, Phytomedicine 19, pp. 364-368. (2012).

[16] G. Zhang, S. Sun, T. Zhu, Z. Lin, J. Gu, D. Li, Q. Gu. Antiviral isoindolone derivatives from an endophytic fungus Emericella sp. associated with Aegiceras corniculatum, Phytochemistry 72, pp. 1436-1442. (2011).

[17] A.W. Indrianingsih, S. Tachibana. $\alpha-$ Glucosidase inhibitor produced by an endophytic fungus, Xylariaceae sp. QGS 01 from Quercus gilva Blume, Food Science and Human Wellness 6, pp. 8895. (2017).

[18] J.I. Kim, H.Y. Kim, S.G. Kim, K.T. Lee, I.H. Ham, W.K. Whang. Antioxidant compounds from Quercus salicina Blume stem. Arch. Pharm. Res., 31, pp. 274278. (2008).

[19] A.W. Indrianingsih, S. Tachibana. Bioactive constituents from the leaves of Quercus phillyraeoides A. Gray for $\alpha$ glucosidase inhibitor activity with concurrent antioxidant activity, Food Science and Human Wellness 5 (2), pp. 85-94. (2016).

[20] Y.M. Kim, Y.K. Jeong, M.H. Wang, W.Y. Lee, H.I. Rhee. Inhibitory effect of pine extract on $\alpha$-glucosidase activity and postprandial hyperglycemia, Nutrition 21, pp. 756-761. (2005).

[21] J.J. Doyle, J.L. Doyle. Isolation of plant DNA from fresh tissue, Focus 12, pp. 1315. (1990).

[22] K. Yamamoto, A. Konoshita, A. Shibahara. Gas chromatographic separation of fatty acid methyl esters on weakly polar capillary columns, $J$. Chromatogr. A 1182, pp. 132-135. (2008).

[23] N. Zhang, C. Zhang, X. Xiao, Q. Zhang, B. Huang. New cytotoxic compounds of endophytic fungus Alternaria $s p$. isolated from Broussonetia papyrifera (L.) Vent, Fitoterapia, 110, pp. 173-180. (2016).

[24] J. Lou, R. Yu, X. Wang, Z. Mao, L. Fu, Y. Liu, L. Zhou. Alternariol 9-methyl ether from the endophytic fungus Alternaria sp. Samif01 and its bioactivities. Braz. J. Microbiol. 47(1), pp. 96-101. (2016).

[25] H. Sugihara, M. Nagao, T. Harada, Y. Nakajima, K. Tanimura-Inagaki, F. Okajima, et al. Comparison of three $\alpha$ glucosidase inhibitors for glycemic control and bodyweight reduction in Japanese patients with obese type 2 diabetes, J. Diabetes Investig. 5, pp. 206212. (2014).

[26] T.H. Nguyen, B.H. Um, S.M. Kim. Two unsaturated fatty acids with potent $\alpha$ glucosidase inhibitory activity purified from the body wall of sea cucumber (Stichopus japonicus), J. Food Sci. 76, pp. H208-H214. (2011).

[27] N. Artanti, S. Tachibana, L.B.S. Kardono, $H$. Sukiman. Isolation of $\alpha$-glucosidase inhibitors produced by an endophytic fungus, Colletotrichum sp. TSC13 from Taxus sumatrana, Pak. J. Biol. Sci. 15, pp. 673-679. (2012).

[28] L. Liu, M.A. Deseo, C. Morris, K.M. Winter, D.N. Leach. Investigation of $\alpha$ glucosidase inhibitory activity of wheat bran and germ, Food Chem. 126, pp. 553561. (2011).

[29] M. Miyazawa, N. Yagi, K. Taguchi. Inhibitory compounds of $\alpha$-glucosidase activity from Arctium lappa L, J. Oleo Sci. 54, pp. 589-594. (2005). 